\title{
Perceived aesthetic impact of malocclusion in 16-24 year-old adults in the rural areas of India
}

\author{
Charu M. Marya, Amit Rekhi, Ruchi Nagpal, Sukhvinder S. Oberoi, Chandan Dhingra \\ Department of Public Health Dentistry, Sudha Rustagi College of Dental Sciences and Research, Kheri More, Village Bhopani, \\ Faridabad 121002, Haryana, India.
}

Address for correspondence: Dr. Charu M. Marya, Department of Public Health Dentistry, Sudha Rustagi College of Dental Sciences and Research, Kheri More, Village Bhopani, Faridabad 121002, Haryana, India. E-mail: maryacm@yahoo.co.uk

\begin{abstract}
Aim: The purpose of this study was to assess the self-perception of patients toward their dental appearance using the aesthetic component (AC) of index of orthodontic treatment need (IOTN) index and whether age and gender had any influence on it. Methods: A cross-sectional study was carried out to assess the perceived esthetic impact of malocclusion in 16-24 year-old subjects selected from the rural population of Faridabad, Haryana, India. The sample was divided into two groups, older adolescents and younger adults, and the AC of the IOTN index was applied. Results: The results showed that most subjects scored themselves as having an attractive dentition with no need for orthodontic treatment (60.91\%). Gender-wise differences were not found to be statistically significant in relation to the perceived needs $(P=0.095)$, whereas age-wise differences were found to be statistically significant in relation to the perceived needs $(P<0.001)$. Conclusion: While the age seemed to have an impact on the perceived esthetic impact of malocclusion, the gender did not seemingly influence this self-perception.
\end{abstract}

Key words:

Esthetic component, index of orthodontic treatment need, self-perception

\section{INTRODUCTION}

Human self-esteem is influenced by acceptable physical appearance, including the condition of the teeth. Further, well-aligned teeth and a pleasing smile reflect positively at all social levels, while irregular or protruding teeth reflect negatively. The major desire for orthodontic treatment is usually related to aesthetics, and to look attractive for self-esteem. Altered dentofacial esthetics and malocclusion less frequently compromise oral function but can influence a person's self-esteem, emotional development, and social integration worldwide..$^{[1-3]}$

\begin{tabular}{|c|l|}
\hline \multicolumn{2}{|c|}{ Access this article online } \\
\hline Quick Response Code: & Website: \\
\hline & www.parjournal.net \\
\cline { 2 - 2 } & \\
\hline & DOI: \\
\hline & $10.4103 / 2347-9264.139701$ \\
\hline
\end{tabular}

Although dissatisfaction with dental appearance is broadly related to occlusal irregularities, ${ }^{[4,5]}$ there are differences in the recognition and evaluation of the dental features. ${ }^{[6,7]}$ Studies revealed that people seem aware of their malocclusion trait, but they do not perceive a need for treatment to the same extent as a dentist or an orthodontics. ${ }^{[8,9]}$

Facial features may be viewed differently in different races and what is considered as pleasing in one race might not be so in another race..$^{[10]}$ The perception of beauty not only is an individual preference, but also might have cultural and ethnic biases. ${ }^{[1-13]}$ Cultural, social and psychological factors and personal perceptions influence what an individual might consider to be physically attractive. It has been seen that physical attractiveness plays a major role in social interaction and influences the impression of an individual's social skill. ${ }^{[14,15]}$

It has also been suggested that age, gender, and socio-economic background are factors playing a role in the self-perception of dental appearance. ${ }^{[16,17]}$ Dentofacial esthetics is an important motivational factor to seek orthodontic treatment, therefore, an improvement in appearance should be an essential treatment goal. 
Personal esthetic perceptions of the dentofacial complex and the associated psychosocial need are directly reflected in perceived need for orthodontic care. Treatment is, therefore, often influenced more by demand rather than by need. ${ }^{[18]}$ In the past, orthodontic treatment need was evaluated from a strictly professional viewpoint (normative need), but several studies have stated that self-perceived dental appearance is also important in the decision to seek orthodontic treatment. ${ }^{[19-21]}$

Although dissatisfaction with dental appearance is broadly related to the severity of the occlusal irregularities, there are differences in the recognition and evaluation of the dental features. ${ }^{[14,22]}$ For this reason, professional opinions regarding evaluation of facial esthetics may not coincide with the perceptions and expectations of patients. ${ }^{[23,24]}$

The aims of present study were to:

- Assess self-perceived dental appearance among rural Indian population using aesthetic component (AC) of the index of orthodontic treatment need (IOTN) index

- Determine if gender and age influence patient self-perception.

\section{METHODS}

\section{Ethical considerations}

The study protocol was approved by Institutional Ethical review committee of Sudha Rustagi College of Dental Sciences and Research, Faridabad. Voluntary consent was obtained from each participant before the study.

\section{Study population}

A cross-sectional study was carried out to assess the perceived aesthetic impact of malocclusion in 16-24 year-old subjects selected from the rural population of Faridabad, Haryana, India. A pilot study was conducted to assess the methodology and to estimate the sample size. A sample size of 990 was calculated to be satisfactory. Older adolescents and younger adults were selected since they are at an age when facial aesthetics including those of teeth are of importance. A stratified two-stage cluster sampling technique with villages as the primary sampling unit was utilized. All subjects between 16 and 24 years old, willing to participate and to give their consent, were selected. Subjects with presence of mixed dentition, any structural abnormality in the teeth concerned and those undergoing or with a history of any orthodontic treatment were excluded. The study was conducted from July to November 2013.

The perceived orthodontic treatment need was assessed using the AC of IOTN. ${ }^{[25]}$

All readings were recorded on a specially prepared form.

\section{Calibration of examiner}

A single calibrated examiner performed all measurements. The intra-examiner test was performed in the measurement of the IOTN-AC. Reliable results were seen with $\kappa=0.82$.

\section{INDEX OF ORTHODONTICTREATMENT NEED-AESTHETIC COMPONENT ${ }^{[26]}$}

Each subject was shown 10 colored photographs depicted in the AC of IOTN [Figure 1] and was asked to choose the one with the closest resemblance to their actual smile. This was done on memory recall basis, and the subjects were not allowed to check their smile in the mirror. The score of the chosen photograph was used to determine the perceived need for orthodontic treatment. A definite need of treatment was represented by photos 8-10, while borderline and no need for orthodontic treatment were represented by photos by photos $5-7$ and 1-4, respectively.

\section{Statistical analysis}

The data was analyzed using the SPSS software (version 11.5) (SPSS Inc., Chicago, IL, USA). Bivariate analyses using the Chi-square test $\left(\chi^{2}\right)$ at 5\% significance level were performed to test the influence of age and gender on perceived orthodontic treatment needs.

\section{RESULTS}

Table 1 shows the age-wise and gender-wise distribution of study population. A total of 528 males (53.33\%) and 462 females (46.67\%) were selected. Of these, 210 males $(49.65 \%)$ and 213 females $(50.45 \%)$ were in the age group of 16-18 years, whereas 318 males (56.08\%) and 249 females $(43.92 \%)$ were in the age group of 18 years old and above.

Table 2 represents the distribution of the individual scores according to the IOTN-AC index. Maximum number

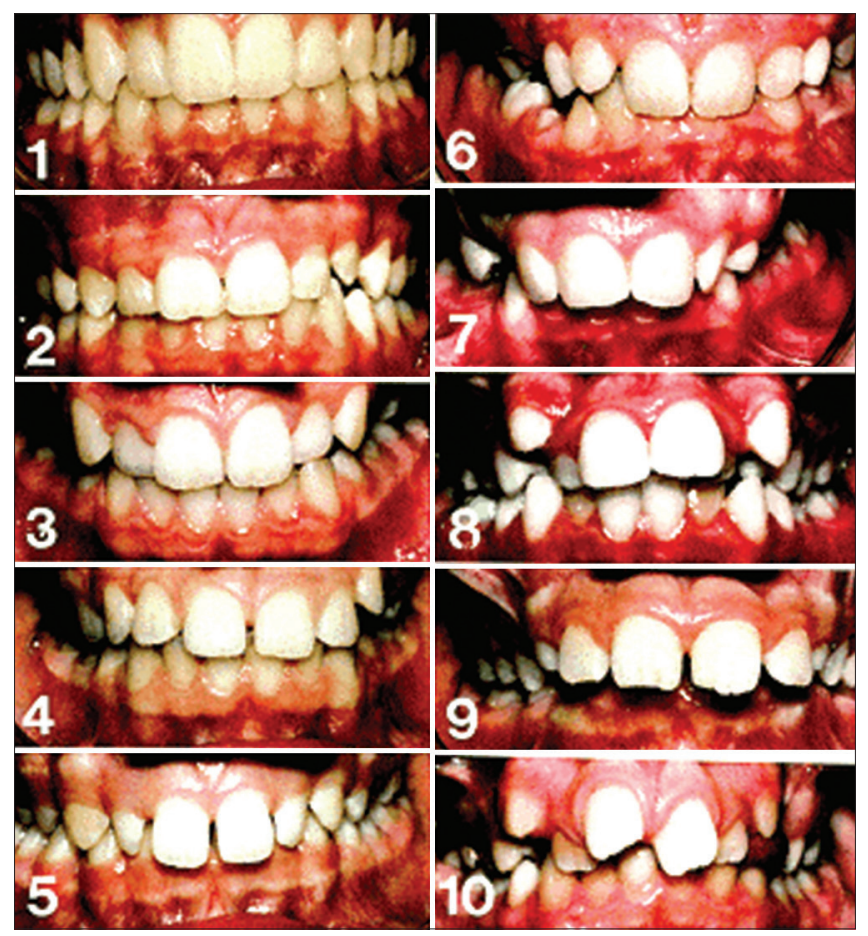

Figure 1: Photographs depicted in the esthetic component of the index of orthodontic treatment need (IOTN) 
of subjects $(n=165)$ reported a score of 3 , followed by score $1(n=156)$. Score 10 was reported by least subjects $(n=24)$.

When the IOTN-AC scores are divided into three categories based on the need for orthodontic treatment, maximum subjects were found to report scores of 1-4 (60.9\%), followed by scores 5-7 (27\%) and scores 8-10 (12.1\%).

Table 3 represents the gender-wise differences according to the IOTN-AC scores. The differences were not found to be statistically significant in relation to the perceived needs $(P=0.095)$.

Table 4 summarizes the perceived orthodontic need IOTN-AC scores according to age groups. The age wise differences were found to be statistically significant in relation to the perceived needs $(P<0.001)$. Significantly greater proportion of the older adolescents $(60 \%)$ showed perceived orthodontic treatment.

\section{DISCUSSION}

The sample analyzed composed of older adolescents and younger adults ranging in age between 16 and 24 years old. People of this age range tend to be more socially aware and conscious about their appearance than a comparatively younger school going population. Further, young people tend to show less physiological wear, wasting diseases, and periodontal diseases in their teeth which if present might affect the accuracy of the method.

In this study, it appeared that the gender of the patients did not influence the perception of their own dentition. The female and male subjects of both age groups had a tendency to score their dental appearance more favorably and allocate themselves toward the more attractive end of the scale.

When self-perceived orthodontic treatment need was evaluated by means of the AC of IOTN, only $12.12 \%$ of the subjects self-scored as presenting a definite need for orthodontic treatment. Consistent to some other studies, no statistically significant differences were observed in perceived orthodontic needs according to gender. ${ }^{[15,18]}$ However, these findings were not consistent to those of other studies. ${ }^{[24,27-30]}$ This is probably because subjects were from a rural area and had a general lack of awareness of the presence of malocclusion. The race, level of expectations (probably affected by their culture), and socioeconomic status of each population might also contribute to this.

Statistically significant differences were found for perceived needs according to age. Significantly greater part of the older adolescents (60\%) self-scored as presenting a definite orthodontic treatment need compared to younger adults. Similar findings were observed in a study conducted by Alhaija et al. ${ }^{[30]}$ where significant differences were found when age groups were compared for the perceived need for treatment. However, this is in contradiction with some other studies ${ }^{[16,24,28,29]}$
Table 1: Age-wise and gender wise distribution of study population

\begin{tabular}{lcccccccc}
\hline & \multicolumn{2}{c}{ Male } & & \multicolumn{2}{c}{ Female } & & \multicolumn{2}{c}{ Total } \\
\cline { 2 - 3 } \cline { 8 - 9 } \cline { 8 - 9 } & $\boldsymbol{n}$ & $\%$ & & $\boldsymbol{n}$ & $\%$ & & $\boldsymbol{n}$ & $\%$ \\
\hline 16-18 years & 210 & 49.65 & & 213 & 50.45 & & 423 & 100 \\
$>$ 18 years & 318 & 56.08 & & 249 & 43.82 & & 567 & 100 \\
Total & 528 & 53.33 & & 462 & 46.67 & & 990 & 100 \\
\hline
\end{tabular}

Table 2: Distribution of the IOTN-AC scores in the study population

\begin{tabular}{lcc}
\hline IOTN score & $\boldsymbol{n}$ & Percentage \\
\hline 1 & 156 & 15.8 \\
2 & 150 & 15.2 \\
3 & 165 & 16.7 \\
4 & 132 & 13.3 \\
5 & 120 & 12.1 \\
6 & 93 & 9.4 \\
7 & 54 & 5.5 \\
8 & 60 & 6.1 \\
9 & 36 & 3.6 \\
10 & 24 & 2.4 \\
Total & 990 & 100.0
\end{tabular}

IOTN: Index of orthodontic treatment need,AC:Aesthetic component

Table 3: Gender wise distribution of the IOTN-AC scores

\begin{tabular}{lcccccccc}
\hline \multirow{2}{*}{ Gender } & \multicolumn{2}{c}{ Male } & & \multicolumn{2}{c}{ Female } & & \multicolumn{2}{c}{ Total } \\
\cline { 2 - 3 } \cline { 8 - 9 } & $\boldsymbol{n}$ & $\%$ & & $\boldsymbol{n}$ & $\%$ & & $\boldsymbol{n}$ & $\%$ \\
\hline Score 1-4 & 315 & 52.24 & & 288 & 47.76 & & 603 & 100 \\
Score 5-7 & 156 & 58.42 & & 111 & 41.58 & & 267 & 100 \\
Score 8-10 & 57 & 47.50 & & 63 & 52.50 & & 120 & 100 \\
Total & 528 & 53.33 & & 462 & 46.67 & & 990 & 100 \\
\hline
\end{tabular}

$P=0.095$. IOTN: Index of orthodontic treatment need, AC:Aesthetic component

Table 4: Age-wise distribution of the IOTN-AC scores

\begin{tabular}{|c|c|c|c|c|c|c|}
\hline \multirow[t]{2}{*}{ Age } & \multicolumn{2}{|c|}{$16-18$ years } & \multicolumn{2}{|c|}{$>18$ years } & \multicolumn{2}{|c|}{ Total } \\
\hline & $n$ & $\%$ & $n$ & $\%$ & $n$ & $\%$ \\
\hline Score 1-4 & 234 & 38.81 & 389 & 61.19 & 603 & 100 \\
\hline Score 5-7 & 117 & 43.82 & 150 & 56.18 & 267 & 100 \\
\hline Score 8-10 & 72 & 60 & 48 & 40 & 120 & 100 \\
\hline Total & 423 & 42.73 & 567 & 57.27 & 990 & 100 \\
\hline
\end{tabular}

$P<0.00$ I. IOTN: Index of orthodontic treatment need, AC:Aesthetic component

where significant differences were not seen. Adolescence is the time when concern over appearance and facial attractiveness is developing, which translates to an increased awareness of body image. Teenagers, in particular have been found to attach great importance to an attractive dental appearance. The differences between studies may result from ethnic variation and the age range of the adolescents in this present study. Ethnicity does have an effect on self-perceived need due to differences in acceptable facial appearances and what is deemed as acceptable occlusion by different ethnic groups. It would thus be useful to validate the IOTN in different ethnic groups. 
Disease does not always negatively affect subjective perceptions of well-being, and even when it does, its impact depends on expectations, preferences, material, social and psychological resources and more importantly, socially and culturally derived values. ${ }^{[9]}$ What is considered aesthetically pleasing in one culture will often not match that which is thought of as aesthetically pleasing in another. Thus, the lack of perceived need in the population evaluated might be because this rural population probably does not have the same notions of beauty as their British peers, where the index was developed. The level of education may also be a factor influencing perceived treatment need and demand. ${ }^{[18]}$

It is possible that subjects replied defensively and subconsciously trying to allocate themselves to the attractive side in order to avoid treatment. Alternatively since each picture shows the dentition only from the front, it is possible that the patients could not differentiate between some features of malocclusion as increased overjet and deep bite and subsequently they could not score. It might be that patients could not estimate the malocclusion and subsequently could not classify the teeth in any of these grades. Further, it is likely that the IOTN is not sensitive enough to account for all types of malocclusion as Class III, open bite, cross bite and scissors bite. ${ }^{[29]}$

Epidemiological analysis of the prevalence of various oral health problems has evidenced an enormous lack of data related to malocclusion. This is due to the accumulated treatment needs of the problems of caries and periodontal disease, an issue that is strongly correlated to the current healthcare model as well as to the inequality in access to healthcare services. Thus, those responsible for planning orthodontic treatment in both the public and private sector should concern themselves with the desires of the community as well as with the large body of evidence that supports the importance of facial characteristics in the lives of individuals.

In summary, further studies are required to improve our understanding of self-perceived need for orthodontic treatment, especially in developing countries where different factors than those reported in North American and European countries could be influencing the demand and delivery of orthodontic care. It may even be necessary to use more than one index in an epidemiological study to gather all the required information.

The conclusions derived from this study are of considerable importance for Indian policy makers in their work with planning and implementing public oral health strategies for the rural population of this age group.

\section{REFERENCES}

I. Shaw WC, O'Brien KD, Richmond S. Quality control in orthodontics: factors influencing the receipt of orthodontic treatment. Br Dent J 1991;170:66-8.

2. Burden DJ. The influence of social class, gender, and peers on the uptake of orthodontic treatment. Eur J Orthod 1995; 17:199-203.

3. Perillo L, Esposito M, Caprioglio A, Attanasio S, Santini AC, Carotenuto M. Orthodontic treatment need for adolescents in the Campania region: the malocclusion impact on self-concept. Patient Prefer Adherence 2014;8:353-9.

4. de Paula Júnior DF, Santos NC, da Silva ET, Nunes MF, Leles CR. Psychosocial impact of dental esthetics on quality of life in adolescents. Angle Orthod 2009;79:1 I88-93.

5. Burden DJ, Pine CM. Self-perception of malocclusion among adolescents. Community Dent Health 1995; 12:89-92.
6. Abdullah MS, Rock WP. Assessment of orthodontic treatment need in 5, I I 2 Malaysian children using the IOTN and DAI indices. Community Dent Health 200I;18:242-8.

7. Abdullah MS, Rock WP. Perception of dental appearance using Index of Treatment Need (Aesthetic Component) assessments. Community Dent Health 2002;19:161-5.

8. Abu Alhaija ES, Al-Nimri KS, Al-Khateeb SN. Orthodontic treatment need and demand in 12-14-year-old north Jordanian school children. Eur J Orthod 2004;26:26I-3.

9. Mandall NA, McCord JF, Blinkhorn AS, Worthington HV, O'Brien KD. Perceived aesthetic impact of malocclusion and oral self-perceptions in 14-15-year-old Asian and Caucasian children in greater Manchester. Eur J Orthod 2000;22: 175-83.

10. Marques LS, Pordeus IA, Ramos-Jorge ML, Filogônio CA, Filogônio CB, Pereira LJ, Paiva SM. Factors associated with the desire for orthodontic treatment among Brazilian adolescents and their parents. BMC Oral Health 2009;9:34.

II. Farrow AL, Zarrinnia K, Azizi K. Bimaxillary protrusion in black Americans - an esthetic evaluation and the treatment considerations. Am J Orthod Dentofacial Orthop 1993;104:240-50.

12. Polk MS Jr, Farman AG, Yancey JA, Gholston LR, Johnson BE, Regennitter FJ. Soft tissue profile: a survey of African-American preference. Am J Orthod Dentofacial Orthop 1995; 108:90-101.

13. Mantzikos T. Esthetic soft tissue profile preferences among the Japanese population. Am J Orthod Dentofacial Orthop 1998; I 14:1-7.

14. Claudino D, Traebert J. Malocclusion, dental aesthetic self-perception and quality of life in a 18 to 21 year-old population: a cross section study. BMC Oral Health 2013;13:3.

15. Badran SA. The effect of malocclusion and self-perceived aesthetics on the self-esteem of a sample of Jordanian adolescents. Eur J Orthod 20 10;32:638-44.

16. Shaw WC. Factors influencing the desire for orthodontic treatment. Eur J Orthod 1981;3:151-62.

17. Hamamci N, Basaran G, Uysal E. Dental Aesthetic Index scores and perception of personal dental appearance among Turkish university students. Eur J Orthod 2009;3 I:168-73.

18. Bernabé E, Flores-Mir C. Normative and self-perceived orthodontic treatment need of a Peruvian university population. Head Face Med 2006;2:22.

19. Espeland LV, Stenvik A. Perception of personal dental appearance in young adults: relationship between occlusion, awareness, and satisfaction. Am J Orthod Dentofacial Orthop 1991;100:234-41.

20. Espeland LV, Stenvik A, Medin L. Concern for dental appearance among young adults in a region with non-specialist orthodontic treatment. Eur J Orthod 1993;15:17-25.

21. Pietilä T, Pietilä I. Dental appearance and orthodontic services assessed by 15-16-year-old adolescents in eastern Finland. Community Dent Health 1996;13:139-44.

22. Mugonzibwa EA, Kuijpers-Jagtman AM, van't Hof MA, Kikwilu EN. Comparison between the opinions of Tanzanian parents and their children on dental attractiveness. Angle Orthod 2004;74:63-70.

23. Albino JE, Lawrence SD, Tedesco LA. Psychological and social effects of orthodontic treatment. J Behav Med 1994;17:81-98.

24. Abdullah MS, Rock WP. Perception of dental appearance using Index of Treatment Need (Aesthetic Component) assessments. Community Dent Health 2002;19:161-5.

25. Tsakos G. Combining normative and psychosocial perceptions for assessing orthodontic treatment needs. J Dent Educ 2008;72:876-85.

26. Brook PH, Shaw WC. The development of an index of orthodontic treatment priority. Eur J Orthod 1989; I 1:309-20.

27. Onyeaso CO, Arowojolu MO. Perceived, desired, and normatively determined orthodontic treatment needs among orthodontically untreated Nigerian adolescents. West Afr J Med 2003;22:5-9.

28. Oshagh M, Salehi P, Pakshir H, Bazyar L, Rakhshan V. Associations between normative and self-perceived orthodontic treatment needs in young-adult dental patients. Korean J Orthod 201 I;41:440-6.

29. Aikins EA, Dacosta OO, Onyeaso CO, Isiekwe MC. Orthodontic treatment need and complexity among Nigerian adolescents in Rivers State, Nigeria. Int J Dent 201।;201 I:813525.

30. Abu Alhaija ES, Al-Nimri KS, Al-Khateeb SN. Self-perception of malocclusion among north Jordanian school children. Eur J Orthod 2005;27:292-5.

How to cite this article: Marya CM, Rekhi A, Nagpal R, Oberoi SS, Dhingra C. Perceived aesthetic impact of malocclusion in 16-24 yearold adults in the rural areas of India. Plast Aesthet Res 2014;1:58-61.

Source of Support: Nil, Conflict of Interest: None declared.

Received: 15-05-2014; Accepted: 08-07-2014 